\title{
Foreword: Strategies for Sustainable Language Learning
}

\author{
Peter Yongqi Gu
}

Strategic learning makes language learning more efficient, more effective, and more pleasant than non-strategic learning. Moreover, strategic language learning encourages sustainable, lifelong learning in that it aims to empower learners to become autonomous. The benefits of strategic language learning go beyond the successful learning of language.

In a rapidly changing world with exponentially growing information, the skills of self-reflection, self-management, and self-initiated learning of new knowledge are as important as, if not more important than, well established school knowledge (Perkins, 2014; Scott, 2015). In addition, the basic human skills of being openminded and collaborative are becoming more important than ever in international and intercultural communication. Learning to learn, learning to communicate, and learning to be, are crucial components of 21st century skills. In this sense, strategic language learners have a good chance of becoming proactive, self-regulated, and capable citizens of the future.

Forty years of research on language learning strategies have produced many insights that are informing language learning and teaching practices around the world. We now know how successful language learners plan, monitor, and evaluate their learning to regulate their learning process. We know how successful readers, listeners, and writers make use of strategies to distinguish themselves from their less successful counterparts. We also know how learners learn vocabulary and grammar strategically to achieve desired results. On the other hand, we have come to a point where we need to go deeper than surface level explorations and go beyond the research questions that we have been asking for 40 years.

Before we open up the research agenda, I think it is time to put an end to the conceptual fuzziness fallacy that has done disproportionate damage to the field. Applied linguistics should have grown out of this naivety a long time ago. Fuzziness is a natural feature of human concepts, 
and learning strategies as a construct is no fuzzier than alternative constructs such as 'self-regulation', 'self-regulated learning' (Dinsmore, 2017) or, for that matter, motivation (Murphy \& Alexander, 2000), learning (Alexander et al., 2009) or any other academic concept. Instead of dumping the concept and looking for a clearly definable alternative, or starting a quixotic search for an all-inclusive or short-and-sweet definition of learning strategies, it is much more productive for researchers to work on solutions to the fuzzy nature of language learning strategies (e.g. Gu, 2012; Mizumoto \& Takeuchi, 2018) and to operationalize clearly what they focus on in an empirical study. In other words, I propose that every empirical study should clearly define its construct and specify how exactly operationalization is done. At the same time, however, we should all accept the fact that other researchers might have different ontological and epistemological assumptions which inevitably lead to different conceptualizations and operationalizations of language learning strategies (Dinsmore, 2017).

It is also high time that we go beyond strategy tallying and other surface level exploratory research. Besides descriptive patterns, we need more explanatory and intervention research. Accordingly, theory building is in urgent demand. Besides the skill element of strategic learning, we need to study the will, the thrill (Hattie \& Donoghue, 2016), and the social construction of language learning strategies. Besides zooming in onto the learner and the self-regulatory and other processes of learning, we need to see how specific tasks of language learning are better dealt with strategically. After all, language learning requires different strategies from the learning of mathematics. The importance of the task in strategic performance can never be stressed enough. For example, our brain has learned to meticulously calculate the shape and the positioning of our hand and the strengths we expect to exert, so that the way we pick up a pen is different from the way we pick up a chair. Strategic learners do exactly the same and use strategies to learn a word differently from those in learning grammar. Furthermore, contextual demands, affordances, and constraints work together to mediate the choice and usefulness of strategic learning. More research along these lines is definitely in order. Another area that needs to be done differently is our assessment of learning strategies. So far, strategy assessment has mainly been used for research purposes. Strategy assessment is very much part and parcel of the whole process during the teaching, learning, and use of strategies. In short, a lot has been achieved in the past 40 years and a lot needs to be done in the next few decades.

I am very excited about the future of research on strategic language learning, not least because of the renewed interest in and dedication to the topic as shown in this volume. This volume had its genesis in presentations given at the Second International Conference on Situating Strategy Use: Present Issues and Future Trends, held in Komotini, 
Greece. Each chapter represents a different perspective on this important topic. Much of the research needed, mentioned in the previous paragraph, is addressed in these chapters. The authors include generations of learning strategy enthusiasts. Interestingly, these authors are mostly from Europe, North America, and Asia, which actually reflects the reality of current research efforts around the world. I am sure that incoming research efforts will be more globally representative both in this conference series and in language learning strategy research in general.

\section{References}

Alexander, P.A., Schallert, D.L. and Reynolds, R.E. (2009) What is learning anyway? A topographical perspective considered. Educational Psychologist 44 (3), 176-192.

Dinsmore, D.L. (2017) Examining the ontological and epistemic assumptions of research on metacognition, self-regulation and self-regulated learning. Educational Psychology 37 (9), 1125-1153. See https://doi.org/10.1080/01443410.2017.1333575.

Gu, Y. (2012) Learning strategies: Prototypical core and dimensions of variation. Studies in Self-Access Learning Journal 3 (4), 330-356.

Hattie, J.A.C. and Donoghue, G.M. (2016) Learning strategies: A synthesis and conceptual model. npjScience of Learning 1, npjscilearn201613. See https://doi.org/10.1038/ npjscilearn.2016.13.

Mizumoto, A. and Takeuchi, O. (2018) Modeling a prototypical use of language learning strategies: Decision tree-based methods in multiple contexts. In R.L. Oxford and C.M. Amerstorfer (eds) Language Learning Strategies and Individual Learner Characteristics: Situating Strategy Use in Diverse Contexts (pp. 99-122). New York, NY: Bloomsbury.

Murphy, P.K. and Alexander, P.A. (2000) A motivated exploration of motivation terminology. Contemporary Educational Psychology 25 (1), 3-53. See https://doi.org/ 10.1006/ceps.1999.1019.

Perkins, D. (2014) Future Wise: Educating our Children for a Changing World. San Francisco, CA: Jossey-Bass.

Scott, C.L. (2015) The Futures of Learning 2: What Kind of Learning for the 21st Century? (UNESCO, Education Research and Foresight Working Papers Series No. 14). See http://repositorio.minedu.gob.pe/handle/123456789/3709. 
